\title{
Retinopathy of Prematurity - Bangladesh perspective
}

\author{
M Rahman ${ }^{1}$, L C Saha ${ }^{2}$, M M Hoque $^{3}$, M M Hossain ${ }^{4}$, B H N Yasmeen ${ }^{5}$
}

\section{Dr. Maksudur Rahman \\ Associate professor \\ Neonatology \\ Bangladesh Institute of Child Health (BICH), Dhaka Shishu (Children) Hospital}

${ }^{2}$ Dr. Liton Chandra Saha Associate professor Neonatology BICH, Dhaka Shishu (Children) Hospital, Dhaka

3 Prof. Md. Mahbubul Hoque

Professor

Neonatology

BICH, Dhaka Shishu (Children)

Hospital, Dhaka

${ }^{4}$ Prof. Dr. M Monir Hossain

Professor

Neonatology

BICH, Dhaka Shishu (Children)

Hospital, Dhaka

${ }^{5}$ Prof. Dr BH Nazma Yasmeen

Professor and Head

Dept. of Paediatrics

Northern International Medical

College, Dhaka

Correspondence

Dr. Maksudur Rahman

Associate Professor

Neonatology, Bangladesh Institute of Child health (BICH), Dhaka

Shishu (Children) Hospital.

Bangladesh

Email : maksuddr@gmail.com

\section{Abstract}

Retinopathy of Prematurity (ROP) results in severe visual impairment and blindness in newborns. Now a days with the advancement of the technology to save preterm infants, its incidence is also increasing in both developed and developing countries. Appropriate and timely screening program can prevent ROP and reduces the functional impairment of eyes. Many countries have their guideline for ROP screening. Bangladesh national guideline is still in progress. Hope it will be published soon. In Bangladesh practically nationwide ROP screening was started in 2013. But still most of the screening program is limited to the capital city. Vast majority of neonates who stayed in peripheral districts are still out of screening program and failed to have timely referral. The current efforts of screening program are mainly driven by the private, NGO and the Gov't professional bodies.

Key words : Retinopathy of Prematurity, screening program.

DOI: https://doi.org/10.3329/nimcj.v11i2.54059

Northern International Medical College Journal Vol. 11 No. 2 January 2020, Page 447-452

\section{Introduction}

Retinopathy of prematurity (ROP) is a major cause of blindness in children. It is a vascular disease of the eye unique to preterm infants characterized by failure of retinal blood vessels to grow and develop normally. It results in severe visual impairment and blindness in newborns. ${ }^{1}$

The incidence and severity of retinopathy of prematurity are closely related to lower birth weight and earlier gestational age. ${ }^{2}$ The prevalence has been surveyed in most of the countries and significant variations were observed ranging from 15.6 to $36.4 \%{ }^{3,4}$

Several screening programs has been taken in different countries so that early diagnosis can be done and treatment can be started to prevent and decrease blindness from ROP. The criteria to screening time according to gestational age and birth weight varies in different countries. In Bangladesh practically screening program started in 2013. Then different institutes started their screening program., ${ }^{5,6}$ There are different treatment modalities for the treatment of ROP. Cryotherapy, Laser therapy and anti-vascular endothelial growth factors has been using in the ROP management. ${ }^{7-10}$ This review has been described on ROP including the recent screening status of Bangladesh.

\section{Epidemiology}

The incidence of ROP is different in various studies, because of the variability in study designs, gestational ages of included infants, survival rates, and treatments used. The prevalence differ among developed and developing countries. ${ }^{10-13}$ The incidence of ROP have been demonstrated in the largest study of the multicenter trial of cryotherapy for ROP (cryorop) over the 15 years. ${ }^{11}$ The reported incidence in that study among infants less than $1250 \mathrm{gm}$ was $65.8 \% .{ }^{11}$ For the developing world ROP is an emerging problem. ${ }^{12}$ In India, in a prospective cohort of 552 preterm low birth weight newborns in a tertiary care hospital with or without risk factors, incidence of ROP was found $22.3 \%$ and among them $9 \%$ were found blind due to retinal detachment at 3 years follow up of those treated with laser photocoagulation. ${ }^{13}$ There are some study regarding ROP in Bangladesh demonstrated that the incidence of ROP was 32\%-35\% among hospitalized newborn.?

\section{History}

Epidemic in ROP which means a variation in number of cases seen in different era and in different countries. ${ }^{14,15}$ The first ROP case was described by Terry in 1942 in an infant who had grey, blood vessel-covered membranes behind 
the pupil. The first epidemic was seen in Europe and North America due to unmonitored oxygen supplementation in the late 1940 's and 1950's. ${ }^{14,15}$ After this event overuse of oxygen was stopped and careful administration of oxygen was recommended. ${ }^{10}$

With the uses of pulse oximetry in 1970s, and beyond, oxygen therapy became controlled and it was thought that ROP would disappear. But it was not true. As the sick newborn continued to survive due to the advancement of neonatal services, the incidence of ROP again rose to high level. ${ }^{10}$ This indicated that small for gestational age and very low birth weight correlated more strongly with the occurrence of ROP than did the oxygen administration.

The third epidemic have been found in India and other developing countries which is characterized by severe ROP in survived premature babies. ${ }^{14}$ The causes of this was due to improper neonatal care and lack of proper oxygen admistration. ${ }^{14}$ Therefore, there is a need for strict guidelines of oxygen administration and monitoring and with proper neonatal care. For these ophthalmologists and the retinologists came together to find out an effective treatment of this devastating disorder related to prematurity. ${ }^{14}$

\section{Pathogenesis}

The development of ROP has two phages:

(1) Primary stage or vasoconstrictive phase: This occurs during exposure to hyperoxia and there is also suppression of the normal anterior ward vascularization of the retina. This mechanism of vasoconstrictive and obliterative effect of oxygen is seen predominantly in the developing retinal vessels. This in turn leads to suppression of vascular endothelial growth factor. ${ }^{14,16,17}$

(2) Secondary stage or vasoproliferative phase : This occurs during the shifting from oxygen to room air and involves dilatation and tortuosity of the existing larger vessels with neovascularization and proliferation of new vessels into the vitreous. This is mainly due to the sudden surge in vascular endothelial growth factor levels. ${ }^{14,16,17}$

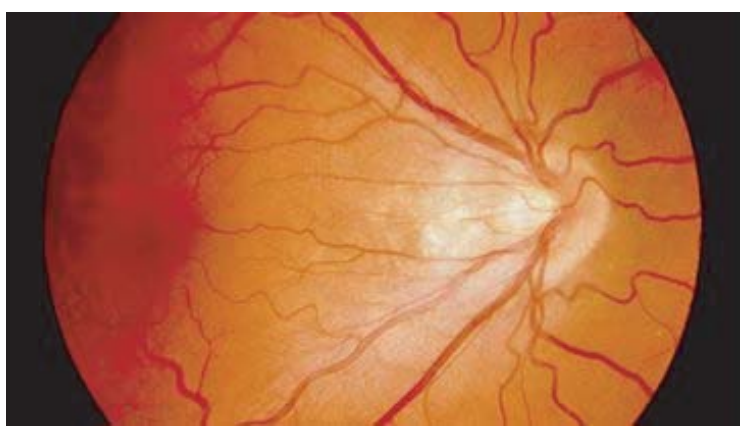

\section{Risk factor}

Premature baby usually develops ROP, but term baby also develops ROP when risk factor is present. Risk factors for ROP includes prolonged oxygen therapy, anemia required blood transfusion, hyperglycemia in $1^{\text {st }}$ week, cardiorespiratory instability, neonatal sepsis etc. ${ }^{10,14}$

\section{Classification}

With the development of modern newborn care and improvement of ventilator care, newborn survival has increased resulting in increase of retinopathy of prematurity. A committee for ROP classification was formed in1984, which proposed an international classification of ROP (ICROP) by dividing the retina into three zones, extending from posterior to anterior retina and describing the extent of ROP in clock-hours of involvement. ${ }^{14,18}$ However with the advances in retinal imaging techniques, a revised ICROP was put forth which described the zones better. ${ }^{14,18}$

\section{Zones}

Three concentric zones centered on the retina define the anteroposterior location of retinopathy.

Zone I: With optic disc as the center, and twice the distance from the disc to fovea, the circle formed is zone I. Using a 25 or 28 diopter (D)-condensing lens, when the nasal edge of the optic disc is kept at one edge, the temporal field of view is zone I extent.

Zone II: It starts from the edge of zone I and extends till the ora serrata nasally, with a corresponding area temporally.

Zone III: Zone III is the remaining crescent of retina temporally.

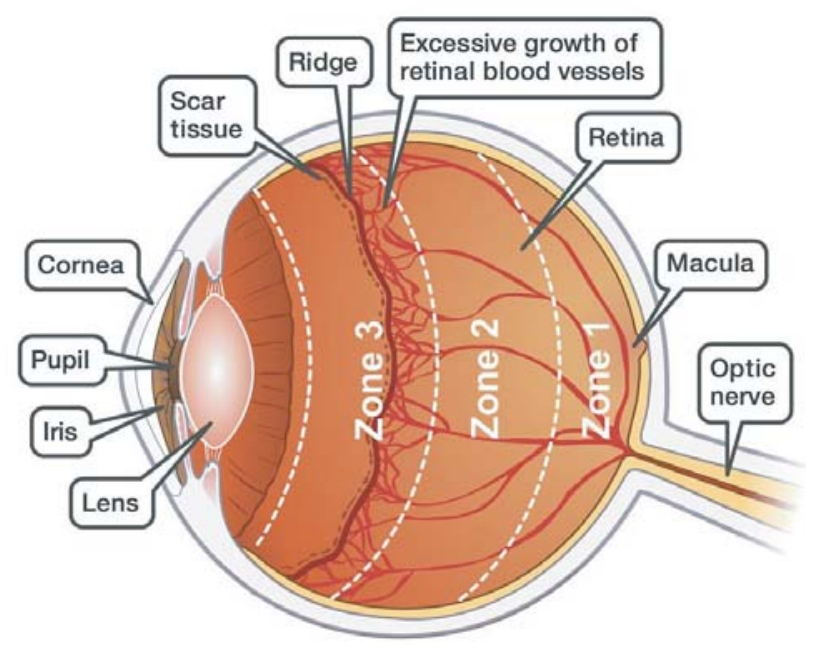

\section{Extent of retinopathy}

The extent of the ROP is documented by the number of clock hours involved. For the observer examining each eye, the temporal side of the right eye is 9 o'clock and that of the left eye is $3 o^{\prime}$ clock and vice versa. ${ }^{14,19}$

\section{Stages of ROP}

It denotes the degree of vascular changes. There are five stages. 
Stage 1 - demarcation line: A demarcation line is seen between the vascular and avascular retina. It is a thin structure that lies in the plane of the retina.

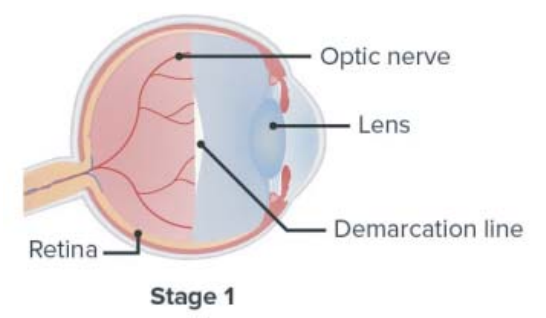

Stage 2 - ridge: The demarcation line grows to occupy a volume and has a height and width to form a ridge above the plane of retina. Small tufts of new vessels also called as "popcorn" vessels may be seen posterior to the ridge.

Stage 3 - ridge with extra retinal fibrovascular proliferation : In this stage extraretinal fibrovascular tissue is seen arising from the ridge into the vitreous. It may be continuous or non-continuous and is posterior to the ridge.
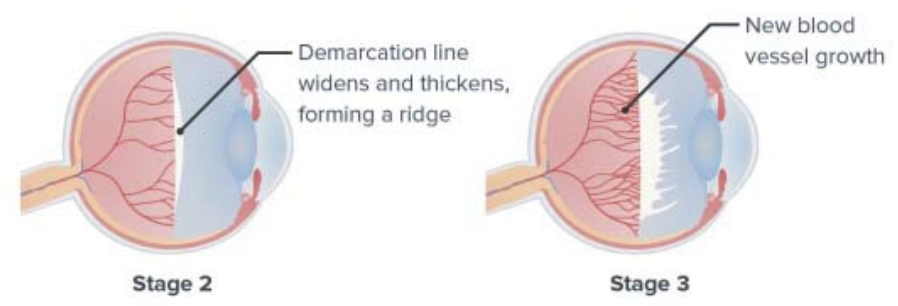

Stage 4 - subtotal retinal detachment : Here a partial detachment of the retina is seen which may be exudative or tractional. It is sub divided into the following: (1) Partial retinal detachment not involving the fovea and (2) Partial retinal detachment involving the fovea.

Stage 5 - total retinal detachment : Here a total retinal detachment is seen as child usually presents with leukocoria (white pupillary reflex). ${ }^{14,19}$
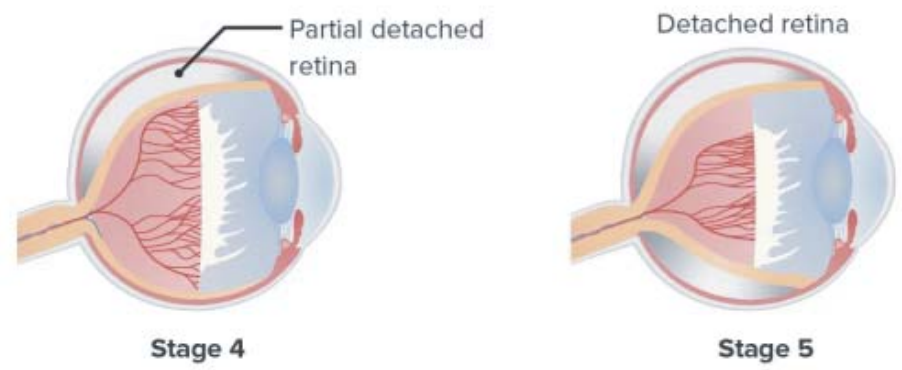

Plus disease : It is an indicator of severity of the disease and is defined as venous dilation and arterial tortuosity of the posterior pole vessels.

Pre-plus disease : It is defined as posterior pole vascular dilation and tortuosity which is more than normal but less than plus disease.
Aggressive posterior ROP : This refers to an uncommon, rapidly progressive, form of ROP previously referred to as "rush disease". It is characterized by a posterior location, severe plus disease and flat intraretinal neovascularization. It can progress very fast to stage 5 ROP and blindness, if not intervened early. The flat neovascularization can be quite subtle and can easily confuse less experienced ${ }^{14,19}$

\section{Screening for ROP - present concept}

Worldwide ROP is the leading causes for childhood blindness. Early detection and timely intervention can be possible by ROP Screening program which ultimately can help to reduce the burden of blindness.

Screening is a process of identifying disease in the apparently normal subjects who are at risk by applying simple, safe, repeatable, sensitive and valid tests for disease detection. Due to lack of gold standard tests for ROP, the screening process may also be referred as "case detection initiative".

Screening ultimately aims at reducing the incidence of ROP, prompt case detection and optimal treatment for ROP, thereby reducing the severity and overall burden of childhood blindness. ${ }^{14,20}$

\section{a) Whom to Screen}

Currently Screening of ROP mainly depends on gestational age, birth weight and some unfavorable factors. The risk factors for ROP include severe respiratory distress syndrome, anemia, neonatal sepsis, thrombocytopenia, multiple blood transfusions and apnea. If these risk factors are not seriously taken into consideration, affected infants may inadvertently get excluded and hence careful review for risk factors should be taken by the pediatrician.

The criteria of ROP screening varies in different countries and different institutes. According to guidelines of the American Academy of Pediatrics, infants with a birth weight $\leq 1500 \mathrm{gm}$ or gestational age of $\leq 30$ week and selected infants with a birth weight between 1500 and $2000 \mathrm{gm}$ or gestational age of more than 30 week with an unstable clinical course, should be screened for ROP. In New Zealand, they recommend screening criteria of $<31$ week' gestation or $<1250$ grams. ${ }^{21-23}$

In developing countries, late preterm babies with a birth weight between 1500 and 2000 grams may also develop ROP. Therefore, in Bangladesh baby with a birth weight $\leq 1750 \mathrm{~g}$ and/or gestational age of $\leq 34$ week may be used as a cut-off for ROP screening. Babies with a gestational age of 34-to-36-week gestation or a birth weight between 1750 and 2000 grams should also be screened if child has a stormy neonatal course. ${ }^{21-23}$

\section{b) Time of screening}

ROP screening should start by 31-week postconceptional age or 4 weeks after birth, whichever is later. In developing countries some babies may develop early aggressive posterior (AP)-ROP. 
Thus, in developing countries, to enable early identification and treatment of AP-ROP, infants $<28$ week or $<1200$ grams birth weight should be screened relatively earlier at 2-3 week of age. ${ }^{14,24}$

\section{c) Follow-up of screening 25}

\begin{tabular}{|c|c|c|c|c|}
\hline Follow -up & $\begin{array}{l}\text { Immature vascularization, } \\
\text { no ROP }\end{array}$ & $\begin{array}{l}\text { ROP } \\
\text { Stage } 1 \text { or } 2\end{array}$ & $\begin{array}{l}\text { ROP } \\
\text { Stage } 3\end{array}$ & $\begin{array}{l}\text { Regressing } \\
\text { ROP }\end{array}$ \\
\hline $\begin{array}{l}1 \text { week or } \\
\text { less }\end{array}$ & $\begin{array}{l}\text { Zone I or immature retina } \\
\text { extends into posterior zone II }\end{array}$ & $\begin{array}{l}\text { Stage } 1 \text { or } 2 \\
\text { zone I }\end{array}$ & $\begin{array}{l}\text { Zone III } \\
\text { Zone II } \\
\text { pre-threshold }\end{array}$ & \\
\hline 1-2 weeks & Posterior zone II & $\begin{array}{l}\text { Stage } 2 \\
\text { zone II }\end{array}$ & & $\begin{array}{l}\text { Unequivocally } \\
\text { regressing ROP } \\
\text { Zone I }\end{array}$ \\
\hline 2 weeks & Zone II & $\begin{array}{l}\text { Stage } 1 \\
\text { zone II }\end{array}$ & & $\begin{array}{l}\text { Unequivocally } \\
\text { regressing ROP } \\
\text { Zone II }\end{array}$ \\
\hline 2-3 weeks & & $\begin{array}{l}\text { Stage } 1 \text { or } 2 \\
\text { zone III }\end{array}$ & & $\begin{array}{l}\text { Regressing ROP } \\
\text { Zone III }\end{array}$ \\
\hline
\end{tabular}

The methods of screening of ROP can be done by Indirect ophthalmoscope and Use of RetCam and telemedicine Screening of ROP. 10,14

\section{Indirect ophthalmoscope}

Here the binocular indirect ophthalmoscope (a head-mounted scope with light source) and a lens for focusing is used. In this method the examination technique involves 2 steps namely the dilatation of pupil and indirect ophthalmoscopy preferably with a $28 \mathrm{D}$ lens. First pupil is dilatated 45 minutes prior to commencement of the screening. Eyes drop, a mixture of cyclopentolate $(0.5 \%)$ and phenylephrine $(2.5 \%)$ is applied 2 to 3 times about $10-15$ min apart. Besides tropicamide (0.4\%) may be used instead of cyclopentolate. ${ }^{10,14}$

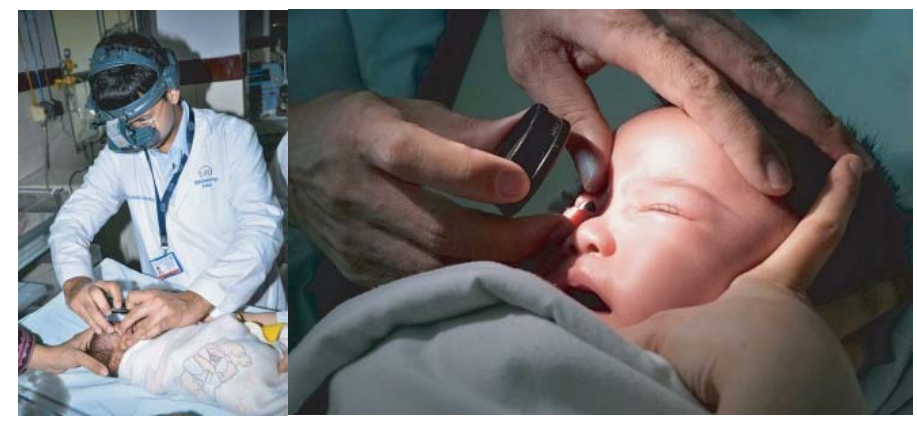

\section{Use of RetCam and telemedicine Screening of ROP}

The RetCam is a camera used to take photograph of the retina of the infants. ${ }^{17}$ This camera does not require a dilated pupil or contact with the eye. Retinal images taken by the camera can be stored, transmitted to expert, reviewed, analyzed and sequentially compared over time and are useful for telemedicine purposes. The advantages of this method are that fewer screening ophthalmologists would be needed, making it ideal for more remote or rural areas. But recent review showed that digital imaging screening cannot replace indirect ophthalmoscopy.

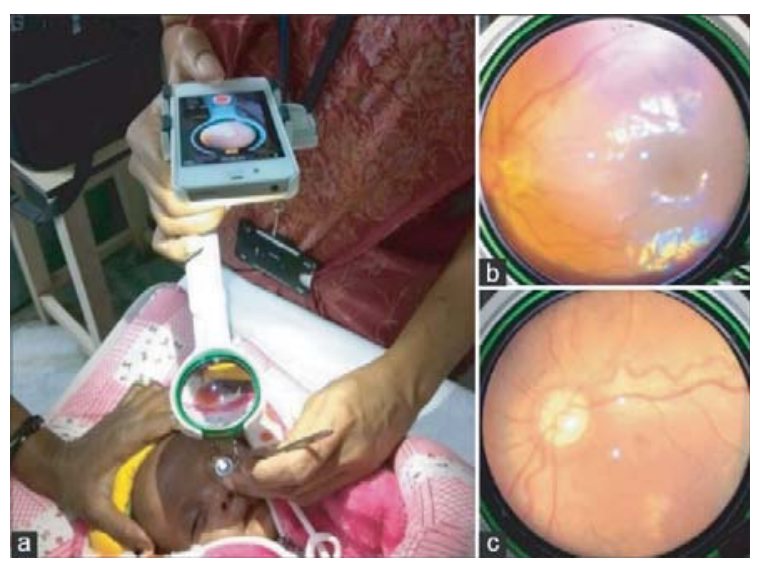

\section{e) Termination of Screening}

Criteria to stop further examination is when full retinal vascularization occur. This usually occurs at about 40th weeks of postmenstrual age and mostly completed by the 45th weeks. Screening should stop when regression of ROP is seen. ${ }^{10,26}$

\section{f) Who should screen}

ROP examinations should be "performed by an ophthalmologist trained in indirect ophthalmoscopy with sufficient knowledge and experience to enable accurate identification of the location and sequential retinal changes of ROP. Other recommended personnel for screening examination are Retina subspecialist, General ophthalmologist trained in indirect ophthalmoscopy, trained Neonatologist/Pediatrician and Trained Technician/Nurses. ${ }^{10,27}$

\section{Treatment modalities}

The management of ROP depends on its zone, stage and aggressiveness. Several treatment modalities are described below.

\section{1) Indirect laser photocoagulation}

Laser photocoagulation of the peripheral retina using indirect delivery system has proved to be the gold standard, time tested and successful means of treatment since many years.

Laser photocoagulation using infra-red diode laser forms a portable mode of treatment and can be performed in the nursery by skilled professionals. The biggest advantage is that it can be done under topical anesthesia. However, many institutions prefer general anesthesia for patient comfort. Laser ablation covers the relatively hypoxic retina into anoxic, thereby reducing stimulus for new vessel formation and disease progression. Cryotherapy or laser photocoagulation, ablation has its own demerits and causes destruction of the retina amounting to significant visual field loss. ${ }^{14}$

\section{2) Anti-vascular endothelial growth factors drugs}

Anti-vascular endothelial growth factor (VEGF) drugs work by directly blocking the effects of VEGF. Various anti-VEGF treatments (bevacizumab) have been used in patients with ROP either by intra vitriol injection or injection into anterior chamber 
of the eye. These drugs show highly successful results in adult retinal vascular diseases. For this reason, its use has been started in pediatric retinopathy as a monotherapy as well as in combination with lasers. A single intravitreal injection is less time consuming and less expensive as compared to lasers. Therefore, Anti-VEGF therapy should be tried only in selected cases. ${ }^{14}$

\section{3) Surgical management}

This option is reserved for advanced stages of ROP (stages 4 and 5). The stage of ROP and features specific to each eye guide the choice of surgical technique. It is shown that best anatomical and visual outcome can be attained if surgical intervention is done at $4 \mathrm{~A} \mathrm{ROP}$ as it halts progression to worse stages.

The surgical options available for stage 4 ROP are lens sparing vitrectomy or scleral buckling. For stage 5, vitrectomy with lensectomy or open sky vitrectomy can be performed. ${ }^{14}$

Visual outcome for stages $4 \mathrm{~B}$ and 5 is poor and can lead to permanent visual impairment. ${ }^{26}$ Periodic follow up and the burden of visual morbidity then become the prime concerns after the retinopathy is adequately treated. Visual rehabilitation can be achieved only through an integrated coordination between the pediatricians, ophthalmologists, paramedics and parents.

\section{4) Newer therapeutic modalities for ROP}

Besides above-mentioned treatment there are many newer modalities of treatment of ROP. Anti-VEGF, systemic propranolol, IGF-1 replacement, granulocyte colony stimulating factor, Jun kinase inhibitor and omega-3 polyunsaturated fatty acid supplementation are the newer modalities. All these have evaluated in animals. Gene therapies also has been tested in animals. These newer emerging therapeutic options can be added with current therapies and improve treatment outcomes. ${ }^{10,14}$

\section{Long term sequelae of Retinopathy of prematurity}

Most of the knowledge about long term outcome of Retinopathy of prematurity came from the study of CRYOROP and ETROP. ${ }^{14}$ Severe retinopathy of prematurity often leads to long-term visual loss and blindness in the most severe cases. ${ }^{10,} 14$

Infants treated with transpupillary laser for severe retinopathy of prematurity have an increased risk of myopia (up to 70\%). Mild to moderate degree of peripheral vision loss (about 6.2\% reduction) has been observed in the lasered versus unlasered eyes. In another the study of CRYO-ROP cohort, between 10 and 15 years of age, new retinal folds or detachments developed in $4.5 \%$ of the threshold eyes treated with cryotherapy and $7.7 \%$ of threshold eyes not treated. Other longterm sequelae seen in other study is cataract, amblyopia, myopia of high degree, strabismus etc, 10,14

\section{Medico legal implications}

By proper and timely screening of ROP, early detection and initiation of treatment can be done. It helps to reduce morbidity from ROP and prevent blindness. Pediatrician and neonatologist should refer the neonates of high risk at appropriate time to ophthalmologist and the ophthalmologist should do the correct screening and treatment. If delay or not doing ROP screening infant may get loss of vision. In that case the pediatrician and the ophthalmologist are at risk of getting into a lawsuit. Therefore, both group should take ROP screening program seriously to avoid medico-legal implications. ${ }^{14}$

\section{Retinopathy of prematurity- Bangladesh perspective}

Every year 3.75 million newborn born in Bangladesh. ${ }^{5}$ Therefore, the chance will be high to develop increase number of ROP in this country. Moreover, heath facility is improving now and more preterm baby survives. But the care of preterm baby is still suboptimum. Hence the risk of ROP is remain. Even term baby with perinatal complication may develop ROP. ${ }^{5}$

One of the earlier studies for ROP in Bangladesh included preterm infants of gestational age $<33$ weeks between December 1998-July 2003 and found an incidence of $5.5 \%$ in 114 babies, all presenting at various stages. Recently in 2017 at Dhaka Shishu (Children) Hospital the incidence of ROP is 35\% among hospitalized neonates. ${ }^{5,7}$

Previously ROP screening was done only in individual level. Very few ophthalmologists did ROP screening in private chamber and hospital and mostly for study purpose. Initially the 2 center, Ispahani Islamia Eye Institute and Hospital (IIEI\&H) and National Institute of Ophthalmology (NIO) started basic services for screening and laser treatment in Dhaka Between 2010 and $2012.5,7$

In 2013, ORBIS International in collaboration with Ispahani Islamia Eye Institute and Hospital (IIEIH) organized a stakeholders' awareness and sensitization program for neonatologists and other child health personnel. With this support from ORBIS development of human resources, infrastructure and equipment was done. In a survey carried out by ORBIS, in 2014 at 12 NICUs of Dhaka, 2962 preterm infants were screened over a six-month period in 2014.

Between January 2013 and March 2017 staff in IIEIH screened over 2000 preterm infants. About a third of these babies had different stages of ROP. ${ }^{5}$

At Dhaka shishu hospital routinely screening program for ROP was started in July 2013 under direct supervision of ophthalmologists of the department of Vitreo-Retina in National Institute of Ophthalmology (NIO). Since then, total 496 hospitalized neonates were screened till December 2018 and the incidence of ROP was $32 \%$ in 2018. In BSMMU the incidence of ROP between 2013 to November 2014 was $23.7 \%$. In BIRDEM the incidence of ROP in 2016 was 33.33\%.28,29 
Currently BSMMU, NIO, IIEI\&H, BIRDEM, Dhaka Shishu hospital and other institutions of Dhaka city are providing ROP services. Also, Bangladesh national society for blinds (BNSB) Eye Hospital, Mymensingh, Deep eye care foundation (DECF), Rangpur and Chittagong eye infirmary and training complex (CEITC), Chittagong are providing ROP service outside Dhaka. 26,30

In Bangladesh, the activities of screening and treatment for ROP is more than previous one. Ophthalmologists and retinologist of Bangladesh namely from major institutes like NIO, IIEI\&H, BSMMU, are working hard for screening and treating ROP. Bangladesh national guideline of ROP screening is still in progress. Hope it will be published soon. ROP isattaining public health significance. But it is limited tothe capital city. Vast majority of neonates who stayed in peripheral districts are still out of screening program and lack of timely referral.

\section{Conclusion}

Newborn survival has increased with the advancement of the modern newborn care in both the developed and developing countries like Bangladesh, resulting in increased incidence of retinopathy of prematurity. For ROP different countries developed their own national screening program. In Bangladesh ROP screening has been started. But there is a significant gap between the increasing need and the limited resources. The current ROP screening program mainly run by the private and NGO sectors. Therefore, we need further large-scale plan for a nationwide sustainable ROP screening program by the government sector.

(all photos: source: internet)

\section{References}

1. Hunter DG, Mukai S. Retinopathy of prematurity: pathogenesis, diagnosis and treatment. IntOphthalmol Clin1992; 32:163-84.

2. Gupta N, Datti NP, Beeregowda Y, Krishnappa K, Krishnamurthy D. Study of incidence, clinical staging and risk factors of retinopathy of prematurity in rural area. J Clin Biomed Sci. 2013; 3: 80-84

3. Lad EM, Hernandez-Boussard T, Morton JM, Moshfeghi DM. Incidence of retinopathy of prematurity in the United States: 1997 through 2005. Am J Ophthalmol. 2009; 148: 451-58.

4. Fortes Filho JB, Eckert GU, Procianoy L, Barros CK, Procianoy RS. Incidence and risk factors for retinopathy of prematurity in very low and in extremely low birth weight infants in a unit-based approach in Southern Brazil. Eye (Lond) 2009; 23: 25-30

5. Nahar N, Badmus S A, Das S K, Malek M I A, mostafizurrahman, khan A M retinopathy of prematurity in Bangladesh: an overview. community eye health. journal 2018; 31(101):26

6. Ahmed A S M N, Muslima H, Anwar K S,Naila Khan N Z,Chowdhury M A K A, Saha K S, and Darmstadt G L. Retinopathy of Prematurity in Bangladeshi Neonates. Journal of TropicalPediatrics.2008;54(5 ): 333-38

7. Saha L C, Hoque M M,Nag D K, Chowdhury MAK A.Screening for Retinopathy of Prematurity in Neonatal Unit - An Experience of a Tertiary Care Hospital in Bangladesh Acad J Ped Neonatol 2017;3(3) : 1-6.

8. Hellen A, Mintz H, Ronald R. Intravitreal injection of Bivacizumab (Avastin) for treatment of stage 3 retinopathy of prematurity in zone I or posterior zone II. Retina 2008;6: 831-38.

9. Hugo Q, Maria A, Martinez C. Antiangiogenic therapy with intravitreal bivacizumab for retinopathy of prematurity. Retina.2008.3: 19-25.
10. Mannan M A, Moni S C, Shahidullah M. Retinopathy of Prematurity (ROP).Current Understanding and Management. Bangladesh J Child Health 2014; 38 (3) : 142-50

11. Cryotherapy for Retinopathy of Prematurity Cooperative Group. Multicenter trial of cryotherapy for retinopathy of prematurity: preliminary results. Arch Ophthalmol.1988; 106:471- 79.

12. Palmer EA, Flynn JT, Hardy RJ, Metz HS, Flynn JT et al. Incidence and early course of retinopathy of prematurity. Ophthalmology. 1991;98: 1628-40

13. Chaudhari S, Patwardhan V, Umesh Vaidya, Kadam S and Kamat A. Retinopathy of Prematurity in a Tertiary Care Center -Incidence Risk Factors and Outcome. Indian Pediatr 2009; 46:2109-22

14. Shah PK, Prabhu V, Karandikar SS, Ranjan R, Narendran V, Kalpana N. Retinopathy of prematurity: Past, present and future. World J Clin Pediatr2016; 5(1): 35-46

15. Sorsby A. The incidence and causes of blindness in England and Wales 19481962. Reports on public health and medical subjects No 114. London: HMSO, 1966

16. Parappil H, Pai A, Mahmoud NA, AlKhateeb MA, Al Rifai H, El Shafei MM. Management of retinopathy of prematurity in a neonatal unit: Current approach. J Clin Neonatol2019;8:203-11.

17. Madan A, Penn JS. Animal models of oxygen-induced retinopathy. Front Biosci2003;8:1030

18. International Committee for the Classification of Retinopathy of Prematurity. The International Classification of Retinopathyof Prematurity revisited. Arch Ophthalmol2005; 123: 991-99

19. Walter M. Fierson, MD, FAAP, Screening Examination of Premature Infants for Retinopathy of Prematurity PEDIATRICS 2018;142(6); 1-5.

20. Wilson CM, Ells AL, Fielder AR. The challenge of screening for retinopathy of prematurity. Clin Perinatol2013; 40: 241-259.

21. Fierson WM; Screening examination of premature infants for retinopathy of prematurity. Pediatrics 2013; 131: 189-195

22. Jalali S, Matalia J, Hussain A, Anand R. Modification of screening criteria for retinopathy of prematurity in India and other middleincome countries. Am J Ophthalmol2006; 141: 966-68

23. Tan Z, Chong C, Darlow B, Dai S. Visual impairment due to retinopathy of prematurity (ROP) in New Zealand: a 22-year review. $\mathrm{Br}$ J Ophthalmol2015; 99: 801-06

24. Quiram PA, Capone A. Current understanding and management of retinopathy of prematurity. CurrOpinOphthalmol2007; 18: 228-34

25. Parveen S, Chetan R, Nishant B. Retinopathy of Prematurity Retinopathy of Prematurity: An Update Sci J Med \& Vis Res Foun 2015; 23(2): 93-96

26. Jalali S, R anand, H kumar, Dorgra MR, Azad EV, Gopal I. Programme planning and screening strategy in retinopathy of prematurity. Indian J Ophthalmol 2003; 51: 89-97.

27. American Academy of Pediatrics, Section on Ophthalmology, Screening examination of premature infants for retinopathy of prematurity. Pediatrics 2006; 117(2):572-76.

28. Shahidullah M, Dey A C, Ahmed F, Jahan I, Dey S. K, Choudhury N. and M. A. Mannan M A. Retinopathy of prematurity and its association with neonatal factors. BSMMU J 2017;10: 1-4

29. Asaduzzaman $M^{1}$, Shamsudduha $A B$, Hoque MM, Jolly FA, Ali TR, Jahan $S$, Kabir MS. Detection of Retinopathy of Prematurity (ROP) in very Low Birth Weight Babies and Outcome of Management Mymensingh Med J. 2020; 29(1):115-120.

30. Dr. Lutful Husain, Retinopathy of Prematurity (ROP) Screening and Treatment Guideline-Bangladesh Status, Orbis International, Bangladesh http:// www.bnfbd.com/presentation-gallery/Dr.Husain ROP(wecompress.com). pdf.(accessed on $02 / 03 / 2019$ ) 